\title{
A (dis)simetrização na alfabetização inicial e sua possível associação com variáveis
}

\section{linguísticas e cognitivas}

\author{
The (dis) symmetrization in initial literacy and its possible association with linguistic and cognitive \\ variables \\ La (dis) simetrización en la alfabetización inicial y su posible asociación con variables linguiísticas y \\ cognitivas
}

Recebido: 09/02/2021 | Revisado: 09/03/2021 | Aceito: 31/03/2021 | Publicado: 10/04/2021

\author{
Lucimauro Palles da Silva \\ ORCID: https://orcid.org/0000-0003-3042-6064 \\ Universidade Estadual do Sudoeste da Bahia, Brasil \\ E-mail: lucimauropalles@gmail.com \\ Ronei Guaresi \\ ORCID: https://orcid.org/0000-0002-8073-2601 \\ Universidade Estadual do Sudoeste da Bahia, Brasil \\ E-mail: roneiguaresi@uesb.edu.br
}

\begin{abstract}
Resumo
Este estudo colabora na descrição do espelhamento, através da avaliação de escolares do último ano da educação infantil e classes de alfabetização, objetivando: a) traçar um parâmetro de incidência de indícios de espelhamento nessas séries, b) relacionar o espelhamento no reconhecimento e na produção escrita de símbolos gráficos e, c) avaliar possíveis associações do espelhamento com variáveis linguísticas ou cognitivas. Hipotetizou-se que indivíduos não nascem naturalmente preparados para relacionar valor sonoro e determinada direção de elementos linguísticos. As variáveis foram: lateralidade, preferência manual, produção de símbolos, sinais de pontuação, letras, números, frases, palavras e escrita do próprio nome. Avaliou-se o reconhecimento de letras, não letras, símbolos de outros sistemas de escrita, letras em outras direções e letras espelhadas, capacidade de leitura, escrita e inteligência. A produção e o reconhecimento foram avaliados com tarefas adaptadas e elaboradas. Participaram da pesquisa 129 escolares de 4 a 12 anos, de ambos os sexos, de creche, escola pública e particular no interior baiano. Os resultados mostraram que escolares que já decodificam apresentam menos produção espelhada e, em contrapartida, sujeitos ainda não leitores apresentam expressivos indícios de espelhamento em produção e reconhecimento. $O$ espelhamento ocorre no processamento visual de quaisquer símbolos gráficos; não ocorre apenas com elementos do sistema escrito e pode permanecer em escolares que já leem. Nas tarefas de produção, quanto maior o grau de escolarização, menores foram os indícios de espelhamento. Na comparação entre segmentos linguísticos, observaram-se indícios de espelhamento em letras e palavras, mas não foram observados em frases.
\end{abstract}

Palavras-chave: (Dis)simetrização; Espelhamento; Alfabetização; Lateralidade; Preferencia manual; Inteligência.

\begin{abstract}
This study collaborates in the description of mirroring, through the assessment of students in the last year of early childhood education and literacy classes, aiming at: a) drawing a parameter of incidence of mirroring evidence in these series, b) relating mirroring in recognition and production writing of graphic symbols and, c) evaluating possible associations of mirroring with linguistic or cognitive variables. It was hypothesized that individuals are not born naturally prepared to relate sound value and a given direction of linguistic elements. The variables were: laterality, manual preference, production of symbols, punctuation marks, letters, numbers, phrases, words and writing of the name itself. The recognition of letters, not letters, symbols of other writing systems, letters in other directions and mirrored letters, reading, writing and intelligence skills were evaluated. Production and recognition were assessed with adapted and elaborated tasks. 129 students from 4 to 12 years old, of both sexes, from day care, public and private schools in the interior of Bahia participated in the research. The results showed that schoolchildren who already decode have less mirrored production and, in contrast, subjects who are not readers yet have significant evidence of mirroring in production and recognition. Mirroring occurs in the visual processing of any graphic symbols; it does not occur only with elements of the written system and can remain in students who already read. In production tasks, the higher the level of schooling, the lower the signs of mirroring. In the comparison between linguistic segments, there were signs of mirroring in letters and words, but they were not observed in sentences.
\end{abstract}

Keywords: (Dis)symmetrization; Mirroring; Literacy; Laterality; Manual preference; Intelligence. 


\begin{abstract}
Resumen
Este estudio colabora en la descripción del mirroring, a través de la evaluación de los estudiantes del último año de las clases de alfabetización y educación infantil, con el objetivo de: a) trazar un parámetro de incidencia de la evidencia del mirroring en estas series, b) relacionar el mirroring en el reconocimiento y producción de escritura de símbolos gráficos y, c) evaluación de posibles asociaciones del reflejo con variables lingüísticas o cognitivas. Se planteó la hipótesis de que los individuos no nacen naturalmente preparados para relacionar el valor del sonido y una determinada dirección de elementos lingüísticos. Las variables fueron: lateralidad, preferencia manual, producción de símbolos, signos de puntuación, letras, números, frases, palabras y escritura del propio nombre. Se evaluó el reconocimiento de letras, no letras, símbolos de otros sistemas de escritura, letras en otras direcciones y letras reflejadas, lectura, escritura e inteligencia. Se evaluó la producción y el reconocimiento con tareas adaptadas y elaboradas. En la investigación participaron 129 estudiantes de 4 a 12 años, de ambos sexos, de guarderías, escuelas públicas y privadas del interior de Bahía. Los resultados mostraron que los escolares que ya decodifican tienen una producción menos reflejada y, en contraste, los sujetos que aún no son lectores tienen evidencia significativa de reflejos en la producción y el reconocimiento. La duplicación ocurre en el procesamiento visual de cualquier símbolo gráfico; no ocurre solo con elementos del sistema escrito y puede permanecer en estudiantes que ya leen. En las tareas de producción, cuanto mayor es el nivel de escolaridad, menores son los signos de reflejo. En la comparación entre segmentos lingüísticos, hubo signos de reflejo en letras y palabras, pero no se observaron en oraciones.
\end{abstract}

Palabras clave: (Des) simetrización; Mirroring; Alfabetización; Lateralidad; Preferencia manual; Inteligencia.

\title{
1. Introdução
}

O valor sonoro de grafemas de sistemas de representação escrita da fala está relacionado à determinada direção dos traços das letras, sendo o espelhamento, entendido como a grafia em outras direções que não a convencionalizada, aspecto sempre presente e, às vezes, preocupante durante o processo de desenvolvimento inicial da leitura e da escrita. Como atestam ano após ano os alfabetizadores, é frequente, no desenvolvimento inicial, o espelhamento, ou a falta de atribuição de valor distintivo à direção das letras, tanto no que diz respeito ao reconhecimento quanto à produção. É sobre esse fenômeno comum da alfabetização inicial a que se dedica este estudo, que objetiva, além de descrever o fenômeno, relacionar reconhecimento e produção e avaliar possíveis associações com outras variáveis linguísticas e cognitivas.

Para Dehaene (2012), a dificuldade no aprendizado da modalidade escrita da língua, entre outros aspectos, situa-se na capacidade de as pessoas realizarem o processo de neuroplasticidade. Para o autor, diferentemente da modalidade oral, o desenvolvimento de sistemas de escrita não é um processo natural, pois a escrita é invenção cultural recente na histórica de nossa espécie, a qual não houve tempo para alterações filogenéticas no nosso sistema nervoso central. Para o autor, para que a leitura se adaptasse ao cérebro foi necessário o recrutamento no cérebro de área biologicamente desenvolvida para o processamento da forma de rostos, num processo que o autor chamou de reciclagem neuronal, comumente processo conhecido como neuroplasticidade. Isso foi possível, entre outras razões, pela potencialidade de o cérebro humano se adaptar à natureza dos estímulos.

[...] as invenções culturais como a leitura se inserem nesta margem de plasticidade. Nosso cérebro se adapta ao ambiente cultural, não absorvendo cegamente tudo o que lhe é apresentado em circuitos virgens hipotéticos, mas convertendo a outro uso as predisposições cerebrais já presentes. [...] Para aprender novas competências, reciclamos nossos antigos circuitos cerebrais de primatas - na medida em que tolerem um mínimo de mudança (Dehaene, 2012, p.20).

A simetrização, entendida como habilidade neurológica de interpretar formas orientadas em espelho como iguais (Dehaene, 2012), mostra-se como um desafio a ser vencido no ensino inicial da leitura e da escrita. Tal competência no processamento visual, a da simetrização dos estímulos visuais, na avaliação do autor, foi desenvolvida ao longo de nossa história evolutiva para que, ao desprezar detalhes de estímulos visuais, a resposta comportamental fosse rápida, colaborando para a subsistência de nossa espécie. Tal competência evolutivamente conquistada, infelizmente atrapalha o aprendizado inicial da leitura e da escrita. Para a alfabetização, principalmente em sistemas de escrita alfabéticos, é necessário dissimetrizar, ou 
seja, nosso sistema de processamento visual deve necessariamente considerar a direção das letras, pois, em nosso sistema de escrita, a direção determina o valor sonoro, como em p, b, q, d, por exemplo. O espelhamento é entendido aqui, portanto, como uma manifestação gráfica de nosso aparato cerebral biologicamente evoluído para simetrizar as informações visuais; à medida que há ensino e/ou estímulos suficientes acerca da direção das letras, ocorre a dissimetrização, processo necessário para o aprendizado de sistemas alfabéticos de escrita que, mesmo indo de encontro à nossa história evolutiva, envolve a adaptação do aparato cerebral para a atribuição de valor distintivo das letras considerando sua direção convencionalizada.

No tocante ao espelhamento, neste estudo temos como motivação a busca de resposta para uma questão mais geral e outras mais específicas. A questão geral busca saber se a simetrização, fenômeno evolutivo-biológico do aparato cognitivo de processamento visual de nossa espécie, elemento em desacordo com a característica distintiva da direção das letras em sistemas de escrita, nesse caso o sistema alfabético da Língua Portuguesa, está associada a variáveis linguísticas e/ou cognitivas. Indícios de simetrização serão levantados neste estudo por meio de tarefas de reconhecimento e produção, avaliadas por meio de visualização (reconhecimento) e escrita (produção) de símbolos gráficos e ditado de letras, números, palavras, frases e escrita do nome.

Os dados, assim como este estudo está delineado, permitirão discutir questões mais específicas como: o espelhamento de letras e palavras está associado a variáveis linguísticas, mais especificamente ao conhecimento das relações entre fala e escrita, considerando as diferentes faixas etárias avaliadas? Espelham-se quaisquer sinais gráficos? Há diferenças entre reconhecimento e produção no que diz respeito à direção de sinais gráficos? A simetrização/espelhamento está associado a inteligência, noções de lateralidade, preferência manual?

Para tanto, nessa perspectiva de avaliar esse fenômeno como resultado de complexo jogo de variáveis, o objetivo geral deste estudo é, portanto, avaliar o necessário processo de dissimetrização dos estímulos visuais para o aprendizado inicial da leitura e da escrita, em escolares do último ano da educação infantil e das classes do ciclo de alfabetização. Nossa hipótese de trabalho é de que, pelo fato de a escrita ser um elemento cultural de nossos tempos, os indivíduos não nascem naturalmente preparados para relacionar valor sonoro e determinada direção de elementos linguísticos, tal fenômeno do âmbito do processamento visual está relacionado a aspectos do âmbito tanto linguístico quanto cognitivo.

Tais resultados permitirão contribuir com a literatura especializada da área sobre a temática, já que, em geral, não apresenta, de modo claro e definido, as características das crianças que estão produzindo as inversões: idade; nível de escolaridade; oportunidades de aprendizagem; tipos de inversões; frequência com que ocorrem; período de tempo em que permanecem na escrita das crianças; se o espelhamento acontece somente com algumas crianças, estabelecendo uma dificuldade individual ou se é um fato que pode ocorrer com a maior parte delas que compromete o processo de aquisição da linguagem.

Ao longo do último século, muitas foram as tentativas na busca de compreender como acontece em nosso cérebro o espelhamento. Em 1920, Samuel Orton constatou que o hemisfério esquerdo é simétrico ao hemisfério direito, porém, segundo ele, esses hemisférios codificam as informações visuais conforme captações inversas, ou seja, quando o hemisfério esquerdo vê um "p" o direito visualiza um "q". Em sua teoria há uma explicação de que o "grupo de células nervosas excitadas por um estímulo visual nos hemisférios direito é a imagem exata em espelho daquele presente no hemisfério esquerdo" (DEHAENE, 2012, p. 288). Outra postulação científica para o espelhamento foi de Corballis e Bealle (1976 apud Dehaene, 2012), de acordo com os autores as confusões em espelho não são erros de percepção e sim podem resultar de uma generalização excessiva, na qual seria possível compreender que nosso sistema visual ao longo da evolução teria incorporado a ideia de que as imagens em espelho são muitas vezes vistas como um só e mesmo objeto, ou seja quando cada hemisfério aprende uma informação visual nova, esse traço de memória é imediatamente enviado ao outro hemisfério (ibidem, p. 292). A hipótese de Orton se sustentou por quase meio século e foi amplamente questionada em suas fragilidades a exemplo da simplicista visão de lateralidade 
hemisférica e também a possibilidade de confusão entre significante e significado. Michael Corballis e Ivan Beale realizaram uma releitura da teoria de Orton afirmando que as descobertas recentes das neurociências confirmam que as áreas visuais dos dois hemisférios analisem inicialmente suas entradas de modos independentes, contudo, a simetria anatômica acontece no momento da transferência dessas informações de um hemisfério para outro. Nesse modelo, a manutenção ativa da simetria do plano cerebral é o mecanismo de elementos que permite a generalização em espelho.

Outra descoberta importante no campo da neuroplasticidade é a descoberta de uma área responsável pelo reconhecimento das palavras ou da área da forma visual da palavra (Word Form Visual Area, ou WFVA) situada na região occipto-temporal ventral do hemisfério esquerdo. Segundo Naschold et al., (2015) há uma sequência de processamento da informação visual no contexto da leitura que envolve essa área:

a) as áreas visuais do lóbulo occiptal dos hemisférios direito e esquerdo efetuam uma primeira análise da imagem para dela extraírem as formas elementares (retas e curvas); b) cerca de 50 milésimos de segundos depois, o resultado dessa análise é enviada para a área do conhecimento visual da palavras WFVA no hemisfério esquerdo, na região occipto-temporal ventral esquerda; c) logo em seguida, ainda no hemisfério esquerdo em região limítrofes à região occipto-temporal ventral esquerda, a leitura acessa o sentido e a sonoridade mediante atividade de dois circuitos principais: um converte os sons, o outro dá-lhes sentido; d) estas vias de leitura ativam as áreas cerebrais distintas nas quais o lóbulo temporal do hemisfério esquerdo, em especial o planum temporal - efetiva o encontro das informações visuais e auditivas. Este planum temporal tem um papel de encruzilhada essencial à aprendizagem da leitura pois ele remete imediatamente para várias outras regiões cerebrais de acesso ao sentido (Naschold, et al., 2015, p. 311-6).

O processo de (dis)simetrização acontece em nível da percepção por neurônios que são responsáveis pela extração da invariância das letras em espelho, estes se localizam na região temporal inferior, onde acontece a reciclagem para a leitura. Para Dehaene (2012), os neurônios responsáveis pela simetrização apresentam maior resistência à simetria horizontal do que a vertical, porém, quando são apresentadas várias orientações de um mesmo objeto a preferência será por uma orientação vertical, como exemplo um neurônio consegue distinguir um "p" de um "b", mas não consegue distinguir um "p" de um "q". Conforme Corballis e Baele, essa invariância faz parte das invariâncias que nossas conexões inter-hemisféricas nos permitem reconhecer de forma espontânea (apud Dehaene, 2012, p. 297).

A letra e sua identificação são similares no aspecto que envolvem a discriminação e categorização da informação visual. Identificação e reconhecimento são tarefas que precisam ser bem situadas neste contexto, no qual a identificação envolve uma decisão de que um objeto com o qual se confronta deve ser colocado em uma determinada categoria cognitiva. Reconhecimento significa que o objeto com o qual nos confrontamos já foi visto antes, embora a identificação possa não estar envolvida (Smith, 2003, p. 137). Segundo esse mesmo autor, dois aspectos distintos ocorrem para identificação das letras: 1) estabelecimento das próprias categorias e, especialmente, nomeação das categorias; 2) identificação das letras, entendida como alocação das várias configurações como diferentes e não funcionalmente equivalentes.

Existem várias possibilidades de compreensão do fenômeno do espelhamento, pois para alguns autores poderá ser indicativo de problemas espaço-temporais, neuropsicomotores, de origem emocional. Para Zorzi (2003), quando a criança inicia seu contato com o sistema escrito, é comum que passe por um período conhecido como "estágio do espelhamento", no qual é comum apresentar uma escrita espelhada de letras e/ou palavras, mesmo que não consiga reconhecer sua produção escrita esteja invertida. Para o autor, há muito o que se descobrir acerca do espelhamento, pois de um lado existe "uma ausência de informações confiáveis e sistemáticas em relação aos espelhamentos e à sua evolução no processo de aprendizagem infantil, embora haja muitas publicações a respeito" (2003, p. 132); para outro, há uma tendência em transformar o espelhamento em patologia, associada à dislexia, como possibilidade de reduzir estudos que busquem de forma mais ampliada uma compreensão do referido fenômeno que, visto no contexto da dislexia, é sempre trabalhado de forma conjunta e 
não individualizada.

Para Gibson et al. (1963), os traços distintivos das letras são aprendidos no primeiro momento por uma capacidade de distinguir objetos que é transferida para a grafia, sendo, esse processo, contínuo com traços não distintivos entre as letras. O trabalho de Cuba dos Santos (1975) apresenta uma concepção da dislexia com a presença de erros clássicos, apontados pela autora e que podem ocorrer tanto na escrita quanto na leitura: confusão entre letras simétricas (p / q; n / u; d / b e g / q); inversão da ordem das letras dentro de uma sílaba (pal/pla) e inversão da ordem das sílabas numa palavra (aeroplano areoplano). Disseminou-se a crença, tanto no meio clínico quanto no meio escolar, de que as inversões de letras poderiam ser indícios definidores da dislexia. Com base na perspectiva psicogenética piagetiana, delineada na pesquisa de Chakur (2005), pode-se explicar a escrita espelhada a partir de outros argumentos, que vão além dos aspectos visoespaciais, e romper com uma explicação de caráter patológico. A referência está calcada nos aspectos próprios do desenvolvimento cognitivo infantil, na construção da noção de realidade, mais especificamente, a noção de permanência e de invariância do objeto. Uma das principais descobertas da criança é a compreensão de que os objetos podem ter uma existência independente e que eles possuem propriedades invariáveis.

Em contrapartida, a partir do desenvolvimento dessa capacidade, uma criança pode reconhecer seus pais, bem como outras pessoas que lhe são familiares, independentemente da posição em que se encontrem. Para estudiosos da área como Mucchielli e Bourcier (1979) e Borel-Maisonny (1984), os espelhamentos de letras são citados como uma das evidências consideradas marcantes, no contexto de sinais da dislexia. Kohler (1984) apresenta uma série de teorias que surgiram para explicar o fenômeno do espelhamento, segundo o qual pode ser compreendido a partir da noção de que existe um conflito entre hemisférios direito e esquerdo; dominância manual, ocular ou auricular contrariadas; distúrbios da organização temporoespacial.

Scliar Cabral (2009) afirma que, quanto menor for o nível do processamento, maior a automatização deve ser durante a aprendizagem. Esse processo é necessário para que a memória não seja sobrecarregada, o que é indesejável, como pode ser visto no sistema de escrita chinês, o qual, dada sua organização mista entre grafemas que correspondem a morfemas e grafemas que sinalizam a pronúncia e as unidades, há um número bastante grande de combinações possíveis, tornando esta tarefa mais difícil para aprendizes da escrita chinesa.

Uma hipótese possível é de que a criança começa a entender a escrita como um objeto qualquer, sem compreender que, neste caso, as posições que as letras ocupam no espaço podem estar determinando diferentes identidades. Portanto, é necessário considerar que esta característica da escrita é arbitrária, convencional e que contraria a realidade. Resultados obtidos em pesquisas neurocientíficas recentes, perspectiva assumida para este estudo, apontam para uma tendência espontânea do sistema visual reconhecer as formas como simétricas, o que Dehaene (2012) aponta como a causa para a percepção de letras espelhadas e rodadas, especialmente as espelhadas, ser uma dificuldade a mais na aprendizagem do sistema escrita em fase inicial da leitura.

Como alternativas para o espelhamento, Zorzi (1998) aponta o treino de habilidades perceptuais na criança para ajudar a compreender que, no caso da escrita, algumas letras podem ter sua identidade modificada dependendo da posição. Para o autor, os espelhamentos e as inversões tendem a desaparecer com certa rapidez quando a criança é orientada sobre a necessidade de se levar em consideração a posição das letras tomando como referência o espaço gráfico. Neste sentido é preciso compreender a localização das margens do papel, a direção (da esquerda para a direita) e o sentido (de cima para baixo) da escrita. Uma vez compreendida a convencionalidade de tal organização espacial, a criança começa a estabilizar a posição e o valor de cada letra. Como possibilidade de confirmação dessa hipótese, Zorzi (1998) empreendeu um levantamento sistemático da escrita de crianças de primeira série em diante, no qual observou que a ocorrência de inversões tem sido a alteração gráfica menos frequente, o que indica que, se um dia as crianças apresentaram espelhamento, não tiveram dificuldade 
em superá-lo, nos outros casos estaria relacionado ao surgimento de outras patologias como a própria dislexia.

Felipe Pegado, especialista na área de investigação em neurociências, em entrevista para a Revista Língua Nostra, apresenta que o "espelhamento" é um dos seus temas de interesse, em um trecho de sua fala ele afirma que:

Outro aspecto que nós estudamos nos últimos anos foi a invariância em espelho, ou seja, quando a criança começa a alfabetização comete um erro frequente: a escrita em espelho. Ela escreve um b ao invés de um d, por exemplo. Esse erro em espelho é na verdade um produto da nossa organização cerebral. O nosso cérebro tem uma representação invariante em espelho. Aliás, não só o cérebro humano, mas o cérebro do macaco e mesmo de outros animais, por exemplo, gato, pombo, a resposta para objetos espelhados - imagem invertida - é equivalente. A representação cerebral tolera essa inversão em espelho, apesar de serem imagens totalmente diferentes ao nível da retina dos seus olhos. Então, essa generalização em espelho atrapalha a alfabetização no aspecto da orientação das letras (ex. d e b, p e q). Isso no começo da aprendizagem é complicado para a criança. Ela faz muito esses erros, é muito típico. Então, o que mostramos em nossas pesquisas é que o cérebro com a aprendizagem da leitura vai perdendo a invariância em espelho para as letras, para as palavras. Com a aprendizagem da leitura o cérebro tem que fazer essa distinção entre a orientação correta das letras para poder ler e escrever (Guaresi, 2016, p. 160).

Outro estudo que auxilia na compreensão do espelhamento é o de Rosa Neto (2013) sobre a lateralidade cruzada, e o desempenho em leitura e escrita de escolares. $\mathrm{O}$ autor verificou que as variáveis do desempenho da leitura e da escrita foram maiores para o grupo das crianças com dominância lateral completa do que para o grupo das crianças com lateralidade cruzada. $\mathrm{Na}$ escrita, houve diferença significante entre os dois grupos, sendo atribuído melhor desempenho às crianças com lateralidade destro-completa. $\mathrm{O}$ autor concluiu que as crianças com lateralidade cruzada apresentam desempenho inferior na leitura e escrita quando comparadas às crianças com dominância lateral completa. Estes dados justificam a relevância do desenvolvimento psicomotor na infância como fator essencial no processo de aprendizagem escolar (ROSA NETO, 2013).

Corballis e Michael (2008) publicaram um estudo intitulado "Equivalência de imagem invertida e reversão interhemisférica de imagem invertida", no qual afirmam que confusões espelhadas são comuns, principalmente em crianças e em alguns casos de comprometimento neurológico. Suas pesquisas sugerem que as confusões em espelho podem ser um impedimento especial em atividades como ler e escrever scripts direcionais, nos quais os padrões de imagem em espelho devem ser distinguidos. Tratar as imagens espelhadas como equivalentes, no entanto, também pode ser adaptável no mundo natural, que não carrega um viés sistemático de esquerda-direita e onde o mesmo objeto ou evento pode aparecer em pontos de vista opostos. No curso da aprendizagem, a equivalência de imagem espelhada pode ser estabelecida através de um processo de simetrização, alcançado através de trocas inter-hemisféricas homotópicas na formação de circuitos de memória. Tais circuitos não distinguiriam entre imagens espelhadas. Aprender a identificar as discriminações na imagem espelhada pode depender das assimetrias cerebrais existentes ou de um aprendizado extenso que substitui o processo de simetrização. $\mathrm{O}$ equilíbrio entre equivalência de imagem espelhada e discriminação de imagem espelhada pode, no entanto, ser precário, com confusões ou reversões espontâneas, como a escrita espelhada, às vezes aparecendo naturalmente ou como uma manifestação de condições como dislexia.

\section{Metodologia}

Esta pesquisa, aprovada por Comitê de Ética, trata-se de um estudo exploratório e, em relação à análise dos dados, pode também ser classificada como qualitativa e quantitativa. Na pesquisa qualitativa, a realidade é múltipla e subjetiva, sendo que as experiências dos indivíduos e suas percepções são aspectos úteis e importantes para a pesquisa, onde a realidade é construída em conjunto entre pesquisador/a e pesquisado/a por meio das experiências individuais de cada sujeito, sendo assim, os pesquisadores entendem que não há neutralidade e que estão, no processo da pesquisa, influenciando e sendo influenciados pelo que está sendo pesquisado. O raciocínio ou a lógica da pesquisa qualitativa é a indutiva, partindo do específico para o 
geral. Não se parte de uma teoria específica, mas ela é produzida a partir das percepções dos sujeitos que participam da pesquisa (Patias e Hohendorff, 2019). O método quantitativo é caracterizado pelo emprego da quantificação na coleta de informações e em seu tratamento através de técnicas estatísticas, garantindo a precisão dos trabalhos realizados e reduzindo as chances de distorções dos resultados. Questionários e entrevistas, geralmente realizam a coleta de dados nesse tipo de abordagem metodológica e apresentam variáveis distintas e relevantes para pesquisa, que em análise é geralmente apresentada por tabelas e gráficos. (Coêlho e Bergamini, 2019). Será exploratória por buscar identificar indícios de espelhamento, bem como sua possível relação com variáveis do âmbito linguístico e cognitivo. Estudos exploratórios configuram-se como fase preliminar do trabalho científico, pois visam explorar o máximo de informações do assunto estudado, delimitar o tema, definir os objetivos, formular hipóteses, descobrir um novo tipo de enfoque para o assunto investigado, não é testar uma hipótese e sim procurar padrões. Não costuma produzir resultados muitos conclusivos ou respostas para determinados problemas, mas indica pesquisas futuras (Costa, 2018).

O estudo buscou avaliar o processo de (dis)simetrização no desenvolvimento inicial da leitura e da escrita, em escolares do último ano da educação infantil e das classes do ciclo de alfabetização. Mais especificamente, a) investigar a incidência de indícios de simetrização, tanto em tarefas de reconhecimento quanto de produção, de elementos do sistema alfabético da Língua Portuguesa e de outros sinais gráficos em escolares do último ano da Educação Infantil e dos primeiros anos de educação formal; b) investigar a relação entre indícios de simetrização e outras variáveis: conhecimento das relações entre fala e escrita; inteligência, noção de lateralidade, preferência manual e sexo.

As variáveis deste estudo são: sexo; noções de lateralidade; preferência manual; inteligência; série; conhecimento do sistema de escrita; indícios de espelhamento - reconhecimento; indícios de espelhamento - produção. O levantamento dos dados ocorreu por meio da aplicação das seguintes ferramentas: ficha de anamnese do desenvolvimento; PROLEC: Provas de Leitura e Escrita; WASI; tarefas de identificação de indícios de espelhamento - reconhecimento; tarefas de identificação de indícios de espelhamento - produção; teste de preferência manual; teste de noção de lateralidade.

O corpus da pesquisa foi composto pelos resultados dos testes acima descritos aplicados a escolares do último ano da educação infantil e do ciclo de alfabetização de um Creche de Educação Infantil e duas Escolas de Ensino Fundamental I, ambas situadas em Vitória da Conquista, uma pública e outra da rede privada que atende alunos da educação infantil e ensino fundamental I. Esses informantes responderam aos testes desde que autorizados pelos seus pais através da assinatura do Termo de Consentimento Livre e Esclarecido (TCLE).

Como informantes para a realização deste estudo, elegeram-se, escolares do último ano da Educação Infantil e dos três anos do ciclo da alfabetização. Essas classes foram escolhidas por considerarmos que é quando se apresenta o sistema de escrita à criança. Ainda, consideramos que um escolar no $3^{\circ}$ ano já teria superado a fase em que são observados indícios de espelhamento.

Os critérios de inclusão para a seleção da amostra foram: a) assinatura do Termo de Consentimento Livre e Esclarecido pelos pais ou responsáveis pelos escolares; b) escolares com desempenho cognitivo dentro dos padrões esperados, esse critério foi avaliado por meio de diálogos com o professor titular dos escolares; c) responder às tarefas de forma autônoma (Silva, 2020).

Os critérios de exclusão para a seleção da amostra foram: a) presença de deficiência cognitiva; b) presença de síndromes genéticas; c) idade discrepante da esperada para a série, com tolerância de apenas 1 ano de atraso e d) escolares cujos pais se recusaram a assinar o Termo de Consentimento Livre e Esclarecido;

Avaliaram-se 129 participantes, sendo 36 alunos, equivalente a 28\%, da Infância III; 38 alunos do $1^{\circ}$ ano, correspondente $29 \% ; 27$ alunos do $3^{\circ}$ ano, o que equivale a $22 \%$ e 28 alunos do $2^{\circ}$ ano, que corresponde a $21 \%$ da população total avaliada. A distribuição por série foi equilibrada. 
Os dados são analisados qualitativamente e quantitativamente, de forma descritiva e correlacional. Os dados das variáveis foram tabulados e calculado o Coeficiente de Correlação de Pearson. Utilizamos como critério de interpretação do coeficiente a proposta de Dancey e Reidy (2006), segundo a qual a correlação será forte se acima de 0,6 (ou -0,6); moderada entre 0,3 a 0,6 (ou $-0,3$ a - -0,6); fraca entre 0,1 e 0,3 (ou -0,1 a -0,3) e a correlação será ínfima ou aleatória abaixo de 0,1 (ou $0,1)$.

\section{Resultados e Discussão}

O primeiro de nossos objetivos de pesquisa é o de investigar a incidência de indícios de simetrização/espelhamento, tanto em tarefas de reconhecimento quanto de produção, de elementos do sistema alfabético da Língua Portuguesa (letras, sílabas, palavras, frases) e de outros sinais gráficos em escolares do último ano da Educação Infantil e dos primeiros anos de educação formal. Dos participantes desta pesquisa, 12\% (15 escolares) não apresentam indícios de espelhamento nem no nível da produção e nem no nível do reconhecimento.

\section{a) Tarefas de reconhecimento}

A (dis)simetrização dos traços foi analisada nessa pesquisa por meio de tarefas de identificação e de produção. As tarefas de reconhecimento, desenvolvidas para fins dessa pesquisa, consistiram na apresentação ao participante de cinquenta pranchas contendo, em cada prancha, 5 elementos, um de cada uma destas categorias: letras, letras de outros sistemas de escrita, números, letras espelhadas - horizontal e verticalmente - e letras em outras direções (ver instrumento em SILVA, 2020). Em cada rodada, era solicitado ao participante olhar a prancha que continha o desenho de algum objeto. Na prancha com a bola era feita uma afirmação e uma pergunta: A palavra bola começa com B. Indique com qual alternativa você começaria a escrever a palavra BOLA. Os participantes eram convidados a indicarem com o dedo com quais elementos começaria escrever a palavra alvo. As 5 alternativas eram das categorias: letras; letras de outros sistemas de escrita; letras espelhadas - horizontal ou verticalmente -; letras em outras direções; e números.

Admitiu-se, no momento das respostas às tarefas de reconhecimento, que o participante indicasse mais de uma alternativa. Ou seja, por mais que o instrumento contasse com 50 itens, por vezes, o participante apresentou um resultado final maior de 50 pontos porque poderia responder mais de uma alternativa. Cinco participantes da pesquisa, de um total de 129 indivíduos, indicaram todas as alternativas como válidas, o que indica um percentual de menos $5 \%$ do total de escolares avaliados.

A Tabela 1 apresenta uma síntese dos dados dessas tarefas de reconhecimento aplicadas aos 129 escolares. A alternativa mais apontada nas tarefas de reconhecimento foi de letras (com média de 8,612), seguida de letras em outras direções $(7,596)$, de letras espelhadas $(7,503)$ e, por fim, do reconhecimento de números $(0,806)$ e letras de outros sistemas de escrita $(0,589)$. 
Tabela 1. Resultado das tarefas de reconhecimento considerando o resultado de todos os participantes do estudo.

\begin{tabular}{|c|c|c|c|c|c|c|c|}
\hline & Média & Mediana & Moda & $\begin{array}{l}\text { Desvio } \\
\text { Padrão }\end{array}$ & Mínimo & Máximo & Contagem \\
\hline 1. Letras & 8,612 & 9 & 10 & 1,710 & 3 & 10 & 129 \\
\hline $\begin{array}{l}\text { Letras de outros } \\
\text { sistemas de escrita }\end{array}$ & 0,589 & 0 & 0 & 0,880 & 0 & 4 & 129 \\
\hline 3. Números & 0,806 & 0 & 0 & 1,031 & 0 & 4 & 129 \\
\hline 4. Letras espelhadas & 7,503 & 8 & 8 & 1,649 & 3 & 10 & 129 \\
\hline $\begin{array}{l}\text { 5. Letras em outras } \\
\text { direções }\end{array}$ & 7,596 & 8 & 8 & 1,632 & 3 & 10 & 129 \\
\hline $\begin{array}{c}\text { Total dos itens } \\
(2,3,4 \text { e } 5)\end{array}$ & 16,496 & 17 & 18 & 3,247 & 8 & 23 & 129 \\
\hline
\end{tabular}

Fonte: Silva (2020).

Comparando os resultados das 5 categorias, observa-se que as médias das categorias letras, letras espelhadas e letras em outras direções se aproximam e estas se distanciam das médias das categorias letras de outros sistemas de escrita e números.

O resultado desse tabelamento intrigou-nos especialmente pelo baixo valor das médias das indicações de reconhecimento da categoria letra, pois isso é indício de falta de conhecimento alfabético dos participantes avaliados. Esse resultado é, ao mesmo tempo, frustrante e preocupante. Frustrante porque percebemos que apenas pequena parcela de nossos participantes, embora com percentual expressivo nos $2^{\circ}$ e $3^{\circ}$ anos, conseguiam decodificar adequadamente e isso, como o leitor poderá verificar a seguir, comprometeu avaliação apropriada das questões de pesquisa deste estudo. É preocupante porque esses dados são uma amostra da situação delicada por que passa a alfabetização nas escolas avaliadas.

Por outro lado, é bem provável que as experiências prévias dos participantes justifiquem em parte esses resultados. Ou seja, os dados sugerem que algumas formas de letras, letras espelhadas e letras em outras direções fazem de alguma forma parte da categoria letras. Enquanto a categoria números apresenta uma funcionalidade específica de quantificação. Na mesma linha de análise, a categoria letras de outros sistemas de escrita apresenta componentes pouco frequentes nas experiências prévias dos escolares participantes desta pesquisa. A nosso ver, isso é indício de conhecimento prévio, de conhecimento basilar do processo de alfabetização que é a distinção entre letras e outros sinais gráficos, competência descrita na BNCC para a Educação Infantil (Brasil, 2017). Quando uma criança chega para a alfabetização, ela vem com um conjunto de conhecimentos próprios de alguém que vivem em ambiente letrado.

Os resultados muito próximos entre letras e letras espelhadas ou em outras direções, a nosso ver, robustecem a tese de que nosso cérebro não evoluiu para reconhecimento das diferentes formas de apresentação dos traços, como afirma Dehaene (2012), por isso uma mesma letra apresentada em sua posição original é vista como verdadeira se apresentada espelhada ou em outra direção.

A Tabela 2 apresenta a média dos resultados das tarefas de reconhecimento distribuída por séries: Infância III, $1^{\circ}$ ano, $2^{\circ}$ ano e $3^{\circ}$ ano. Esses dados reforçam o que já foi mencionado acima acerca da falta de diferença expressiva na indicação da categoria letra e isso, a nosso ver, é novamente indicativo de falta de conhecimento alfabético mesmo em escolares do $2^{\circ}$ e $3^{\circ}$ ano.

As indicações para a categoria letras espelhadas foram também equivalentes entre as turmas, não confirmando o que esperávamos: aumento gradativo nas médias da categoria letras e proporcionalmente diminuição da média da categoria letras espelhadas. No exercício de olhar o desempenho dos participantes que sabiam o valor sonoro das letras, verificamos que os 
participantes que, mesmo precariamente, já decodificavam/codificavam, observamos que o reconhecimento espelhado ainda se mantinha. Ou seja, observamos indício de simetrização/espelhamento mesmo depois da conquista da decodificação/codificação pelos participantes.

Quanto ao reconhecimento de letras espelhadas e letras em outras direções, o percurso é semelhante, havendo uma pequena redução no $3^{\circ}$ ano. Isso, na nossa análise, confirma a consideração acima.

Tabela 2. Média do resultado das tarefas de reconhecimento distribuído por turmas.

\begin{tabular}{|c|c|c|c|c|}
\hline & Infância III & $1^{\circ}$ ano & $2^{\circ}$ ano & $3^{\circ}$ ano \\
\hline 1. Letras & 6,861 & 8,973 & 9,185 & 9,821 \\
\hline 2. Letras de outros sistemas de escrita & 0,694 & 0,342 & 0,481 & 0,892 \\
\hline 3. Números & 0,777 & 0,578 & 0,333 & 1,607 \\
\hline 4. Letras espelhadas & 6,777 & 7,921 & 8,407 & 7 \\
\hline 5. Letras em outras direções & 6,583 & 8,157 & 8,666 & 7,107 \\
\hline Total dos itens $(2,3,4$ e 5$)$ & 14,833 & 17 & 17,888 & 16,603 \\
\hline
\end{tabular}

Fonte: Silva (2020).

No $2^{\circ}$ e $3^{\circ}$ anos, observou-se um fenômeno perceptível no momento da aplicação dos instrumentos, mas que não aparece nos resultados: em geral, a ordem de indicação pelos escolares foi inicialmente a categoria de letras e, em seguida, letras espelhadas e, posteriormente, em outras direções. A nosso ver, esse fato pode ser resultado de frequência de input, já que, em geral, não são frequentes indicações das categorias números e letras de outros sistemas de escrita. A vivência no mundo letrado coloca o indivíduo em contato com outdoors, panfletos publicitários, escrita em brinquedos e placas em que é comum letras da Língua Portuguesa, mas não é comum letras de outros sistemas de escrita. Por outro lado, a ordem da indicação informada acima é, na nossa análise, estabelecimento, mesmo ainda inseguro, das convenções de nosso sistema de escrita, no que diz respeito às direções das letras. Isso nos leva a supor que se os participantes do $2^{\circ}$ e $3^{\circ}$ anos, se tivessem que dar apenas uma resposta, indicariam a categoria letras.

Para o cálculo do Coeficiente Alfa de Cronbach, os resultados de todos os participantes avaliados $(\mathrm{N}=129)$ foram válidos e avaliados nas cinco categorias de reconhecimento: letras, letras de outros sistemas de escrita, números, letras de outras direções e letras espelhadas. O resultado observado foi de 0,59, conforme a Tabela 3.

Tabela 3. Coeficiente de confiabilidade de Cronbach ${ }^{1}$ das tarefas de reconhecimento

\begin{tabular}{ccc}
\hline Cronbach's Alpha & $\begin{array}{c}\text { Cronbach's Alpha Based on Standardized } \\
\text { Items }\end{array}$ & N of Items \\
\hline .59 & .50 & 5 \\
\hline
\end{tabular}

Fonte: Silva (2020).

O resultado observado é significativamente diferente de zero, de modo que as tarefas avaliam aquilo a que se propõem. Souza, Alexandre e Guirardello (2017, p. 652) defendem que valores superiores a 0,30 já podem ser considerados

${ }^{1} \mathrm{O}$ coeficiente alfa de Cronbach foi apresentado por Lee J. Cronbach em 1951. Essa ferramenta de cálculo estatístico, bastante criticada, mas amplamente utilizada, serve para estimar a confiabilidade de instrumentos de avaliação, sua consistência interna e sua fidedignidade. $\mathrm{O}$ coeficiente $\alpha$ é calculado a partir da variância dos itens individuais e da variância da soma dos itens de cada tópico avaliado. A avaliação da confiabilidade é tópico importante na avaliação psicométrica de instrumentos neuropsicológicos. 
adequados para avaliação do constructo. Informam, ainda, que apesar de ser um dos mais utilizados não há consenso quanto a interpretação dos resultados. Apesar disso, defendem que "embora estudos determinem que valores superiores a 0,7 sejam os ideais, algumas pesquisas consideram valores abaixo de 0,70 - mas próximos a 0,60 - como satisfatórios" (2017, p. 651), como é o caso do observado nas tarefas de reconhecimento deste estudo.

\section{b) Tarefas de produção}

Em relação às tarefas de produção, foram elaboradas três tarefas com objetivo de investigar o fenômeno presente no desenvolvimento inicial da leitura e da escrita: a (dis)simetrização dos traços. Os resultados das 3 tarefas totalizavam 50 itens.

A primeira tarefa foi composta de 18 símbolos gráficos que foram apresentados à criança, um a um, seguidos da solicitação para que o participante memorizasse para, em seguida, reproduzir uma cópia na folha de respostas. Esse instrumento foi uma adaptação de Garcia $(2008)^{2}$, cujo objetivo foi o de avaliar o processo de simetrização de um silabário. O seguinte contou com três itens, mais especificamente três sinais de pontuação para, igualmente, o participante memorizar e, em seguida, reproduzir na folha de resposta. A Figura 1 apresenta o conjunto desses 21 itens a que fizemos referência (18 símbolos gráficos e 3 sinais de pontuação).

Figura 1. Símbolos para reprodução gráfica.

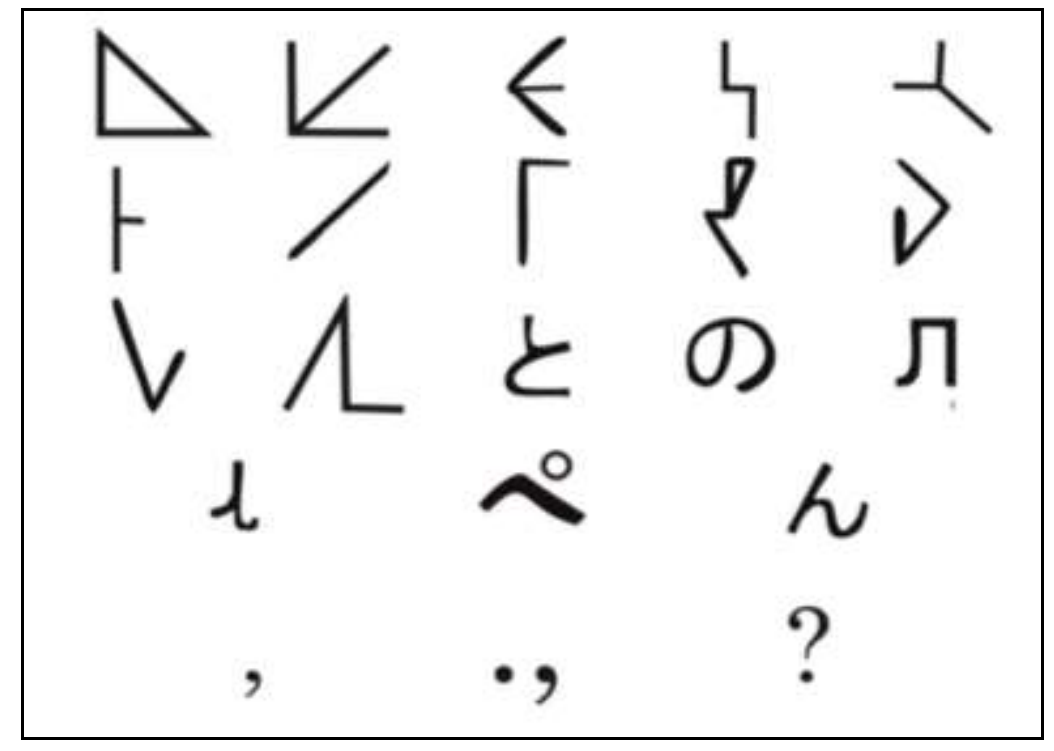

Fonte: Silva (2020).

A segunda tarefa de produção consistiu na solicitação para a criança escrever a partir do ditado oral destes itens: letras (10 itens), números (9 itens), palavras (4 itens) e frases (4 itens). Foi entregue à criança uma página preparada para esta tarefa. Destaca-se que nessa elaboração foram considerados itens (letras, números, frases e palavras) com maior possibilidade de reprodução espelhada: a) letras: E, F, L, M, W, A, B, V, U, D; b) números: 3, 2, 8, 5, 9, 4, 1, 6, 7; c) palavras: Família, Macaco, Sapo, Janela e d) frases: Pipoca pula na panela. O pássaro voa alto. Os animais brincam na chuva. O menino joga bola.

\footnotetext{
${ }^{2}$ Alguns itens são do estudo de Tania Mikaela Gacia, intitulado Neuroplasticidade: o espelhamento de grafemas na leitura de um silabário. O estudo trata-se de tese de doutorado defendida em 2008 na Universidade Federal de Santa Catarina. Disponível em: https://docplayer.com.br/25130993-Reciclagem-neuronal-o-espelhamento-de-grafemas-na-leitura-de-um-silabario.html. Acesso em: 12 set. 2019. A tese foi orientada por Leonor Scliar Cabral. Na nossa versão acrescentamos os sinais de pontuação (, ; e ?) porque consideramos importante investigar se os escolares dessa pesquisa espelhavam também sinais de pontuação.
} 
A última tarefa de produção foi a replicação de estudo de Cornel (1985, apud Dehaene, 2012). Tal estudo consistiu na entrega de uma folha contendo dois pontos, um à direita e outro à esquerda. Em seguida houve a instrução oral para a criança escrever o seu nome a partir dos pontos da folha.

A soma dos diversos itens de produção totalizou 50 itens. A Tabela 4 apresenta uma síntese dos dados dessas tarefas de produção aplicadas aos 129 escolares. A produção adequada foi considerada com a média mais alta 25,046, ou seja, aproximadamente $50 \%$ dos participantes produziram adequadamente a tarefa; a categoria produção parcial obteve média de 13,875; indícios de produção espelhada 3,581 (aproximadamente 7\% das respostas) e ausência de produção com média 7,302.

Tabela 4. Resultado de todas as tarefas de produção considerando o resultado de todos os participantes do estudo.

\begin{tabular}{llcccccc}
\hline & Média & Mediana & Modo & $\begin{array}{c}\text { Desvio } \\
\text { Padrão }\end{array}$ & Mínimo Máximo Contagem \\
\hline 1. Produção adequada & 25,046 & 25 & 23 & 11,057 & 1 & 47 & 129 \\
2. Produção parcial & 13,875 & 15 & 18 & 6,094 & 0 & 27 & 129 \\
3. Indícios de produção espelhada & 3,581 & 3 & 3 & 2,685 & 0 & 12 & 129 \\
4. Ausência de produção & 7,302 & 5 & 0 & 7,583 & 0 & 46 & 129 \\
\hline
\end{tabular}

Fonte: Silva (2020).

$\mathrm{Na}$ Tabela 5 é apresentada a média dos resultados das tarefas de produção distribuída por séries: Infância III, $1^{\circ}$ ano, $2^{\circ}$ ano e $3^{\circ}$ ano. É possível ver um movimento inversamente proporcional entre produção adequada e produção espelhada quando se leva em conta o resultado por séries. Como é possível ver na Tabela 5, há evolução do índice de produção adequada quando se comparam os resultados das séries e, por outro lado, a produção espelhada diminui consideravelmente caindo de 15,611 (infância IIII) para 3,714 ( $3^{\circ}$ ano). No quesito produção parcial também há uma redução com a progressão das séries, de 17,555 na infância III para 10,750 no $3^{\circ}$ ano. A maior diferença observou-se no quesito indícios de produção espelhada que cai de 15,611, na infância III, para 3,714 no $3^{\circ}$ ano.

Tabela 5. Média do resultado das tarefas de produção distribuído por turmas.

\begin{tabular}{|c|c|c|c|c|c|}
\hline & & Infância III & $1^{\circ}$ ano & $2^{\circ}$ ano & $3^{\circ}$ ano \\
\hline 1. & Produção adequada & 12,138 & 28,583 & 30,555 & 31,964 \\
\hline 2. & Produção parcial & 17,555 & 13,684 & 12,481 & 10,750 \\
\hline 3. & Indícios de produção espelhada & 15,611 & 4,131 & 4,407 & 3,714 \\
\hline 4. & Ausência de produção & 4,567 & 3,763 & 2,407 & 3,071 \\
\hline
\end{tabular}

Fonte: Silva (2020).

A diferença nas tarefas de produção do III infantil para o $1^{\circ}$ ano pode ser resultado do aumento mais importante da exposição do indivíduo às convenções de escrita, entendidas à luz da Teoria dos Sistemas Adaptativos Complexos ${ }^{3}$ como atratores estranhos ao sistema. Cabe a ressalva de que as tarefas de produção envolviam elementos linguísticos ( 3 sinais de pontuação, 10 letras, 4 palavras e 4 frases) e não linguísticos (21 símbolos gráficos e 9 números). Todavia, diferentemente do observado nas tarefas de reconhecimento, vemos aqui uma significativa diferença entre os dados da Infância III em relação aos

\footnotetext{
${ }^{3}$ Para mais informações acerca dessa teoria, sugerimos a leitura de Silva (2020).
} 
demais anos do ciclo da alfabetização, em especial da categoria produção adequada (12,3 na Infância III para 28,5 no $1^{\circ}$ ano) e indícios de produção espelhada (15,6 na Infância III para 4,1 no $1^{\circ}$ ano).

O observado nos dados das tarefas de produção, ao que parece, está de acordo com os resultados de Cornel (1985 apud Dehaene 2012), em que boa parte dos indivíduos passa a dissimetrizar os estímulos visuais entre o $6^{\circ}$ e o $7^{\circ}$ ano de idade, especialmente no que concerne à escrita do nome a partir do ponto.

Nas tarefas de produção, foram mostrados sinais gráficos variados e sinais de pontuação, foram ditadas letras, números, palavras e frases e foi solicitado que o participante escrevesse o nome tomando como referência os pontos em uma folha branca. Observaram-se respostas classificadas como espelhadas nas seguintes atividades: Escrita do nome, Ditado de Letras e Números. Não se observou escrita espelhada nas categorias palavra e frase. Ou seja, houve registro de espelhamento em sinais gráficos variados (Figura 2), sinais de pontuação (Figura 3), letras (Figura 4), números (Figuras 5 e 6) e, também, na escrita do nome (Figuras 18, 19 e 20).

Conforme a Figura 2, não observamos muitos indícios de espelhamento quando se avaliou a reprodução de símbolos gráficos, especialmente formas de poucos traços. Todavia, há muitas produções em outras direções, ou seja, observamos que muitos de nossos participantes reconheciam a forma, mas ainda não conseguiam reproduzir no papel a figura na mesma direção que lhe fora apresentada, a figura alvo.

Figura 2. Produção espelhada na reprodução de sinais gráficos variados.

$$
\text { Alvo Produção observada }
$$
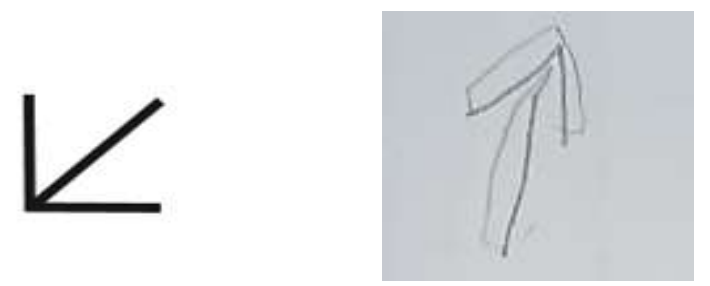

Autor: A.G. 5 anos - primeiro ano do ciclo de alfabetização. Fonte: Silva (2020).

A Figura 3 apresenta exemplos de reprodução espelhada e em outras direções de sinais de pontuação. Quanto à vírgula, provavelmente por ser mais conhecida pelos escolares, não se observou quaisquer indícios de espelhamento. Mais uma vez a Teoria dos Sistemas Adaptativos Complexos colabora para o entendimento desse fenômeno, de não termos observado espelhamento da vírgula e sim dos demais sinais, já que em geral a frequência da vírgula é bastante superior à frequência do ponto e vírgula, por exemplo.

Em se tratando de sinais menos recorrentes, seja no reconhecimento ou na reprodução, como é o caso do ponto e vírgula (;) e interrogação (?), observaram-se algumas reproduções espelhadas. Assim como no reconhecimento, a produção espelhada também se mostrou persistente naqueles participantes com algum conhecimento alfabético. 
Figura 3. Produções espelhadas na reprodução de sinais de pontuação

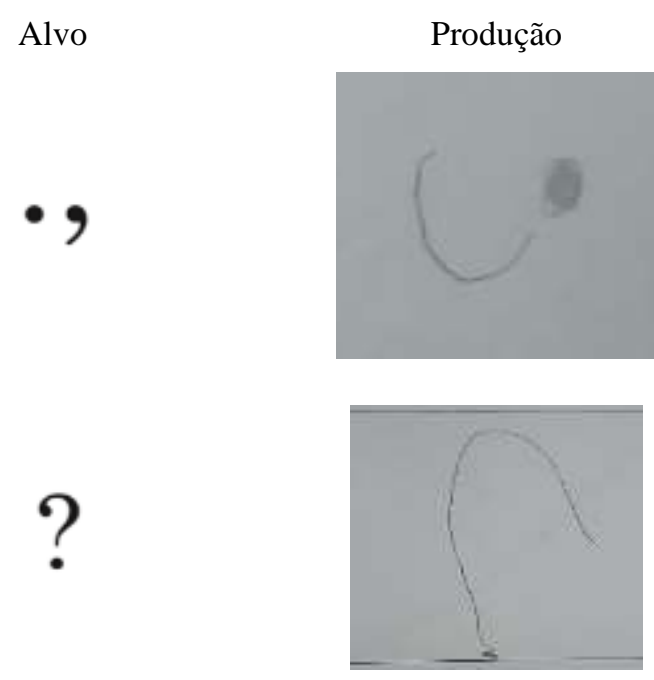

Autor: F.B. 6 anos - último ano da educação infantil. Fonte: Silva (2020).

Na Figura 4, apresenta-se um exemplo de espelhamento de letra observado na tarefa do ditado - produção. Há poucos indícios de espelhamento no nível da letra, provavelmente por fazerem parte do repertório do escolar no início da educação formal. Observamos, também, maior frequência de espelhamento de algumas letras e em menor frequência outras. Várias ocorrências foram observadas com a letra E, conforme Figura 14, que tem semelhanças com número 3, por exemplo.

Figura 4. Produção espelhada na tarefa de ditado de letras.

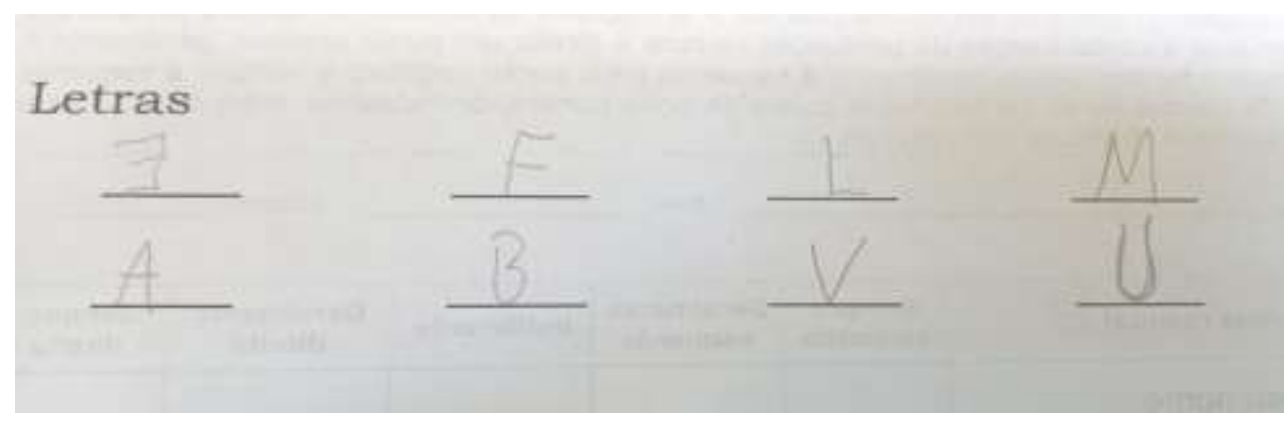

Autor: D.S. 7 anos - primeiro ano do ciclo de alfabetização. Fonte: Silva (2020).

Ao se observar o espelhamento nas tarefas de ditado de números, vimos registros espelhados bastante frequentes nos participantes desta pesquisa. A Figura 5 apresenta exemplo de produção de números com espelhamento, confirmando que muitos escolares que ainda não se apropriaram do sistema de escrita, mesmo conhecendo o valor sonoro de cada numeral, na hora de reproduzir o fazem de forma invertida. 
Figura 5. Produção espelhada na tarefa de ditado de números.

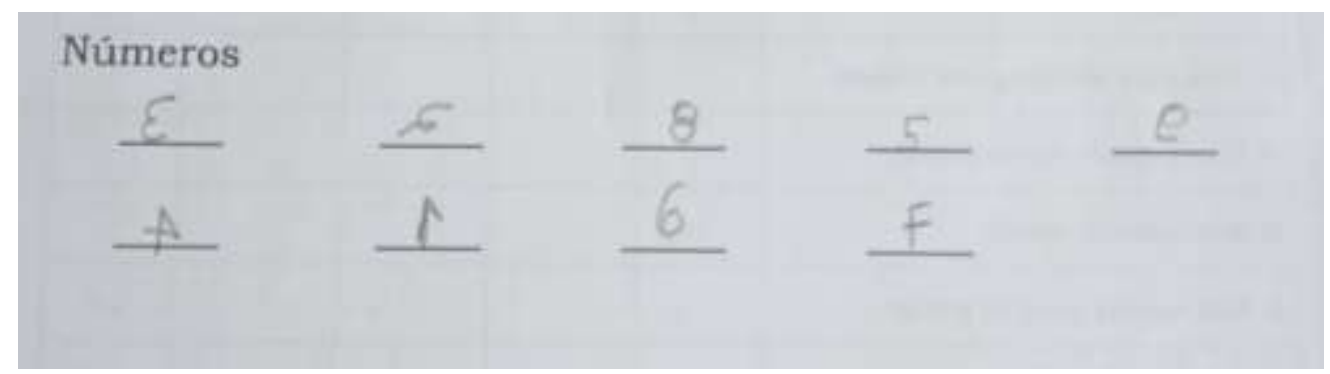

Autor: Y.S. 6 anos - primeiro ano do ciclo de alfabetização. Fonte: Silva (2020).

A nosso ver, esse exemplo confirma, assim como postula Dehaene (2012), de que nosso cérebro não nasce com determinantes acerca da direção distintiva dos traços. Na mesma linha, é necessário neuroplasticidade de áreas cerebrais (a principal delas a região Occipito-temporal ventral do hemisfério esquerdo) para o processamento da direção distintiva dos traços. Ao que parece, os participantes em processo de alfabetização não amadureceram o suficiente não só para reconhecer como também para produzir elementos gráficos nas direções convencionalizadas (Naschold, 2015).

A Figura 6 apresenta um dado de escrita espelhada do nome. Nesse resultado, é possível perceber que, mesmo que o próprio nome já seja conhecido pelos participantes, houve casos que o participante escreveu espelhado.

Figura 6. Produção espelhada na tarefa de Escrita do nome.

\section{TESTE DE ESCRITA}

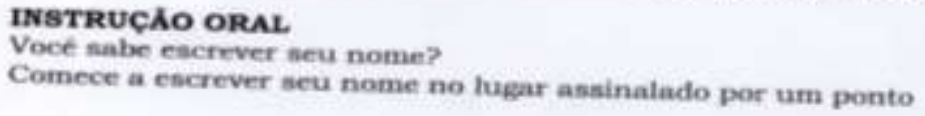

Autor: M.R.S. 5 anos - último ano da educação infantil. Fonte: Silva (2020).

\section{c) Relação entre simetrização e outras variáveis linguísticas e cognitivas}

O segundo dos objetivos específicos deste estudo foi o de investigar a relação entre indícios de simetrização e outras variáveis: conhecimento das relações entre fala e escrita; inteligência, noção de lateralidade, preferência manual e sexo.

O coeficiente de correlação entre as variáveis Indício de produção espelhada de números e a variável conhecimento linguístico (PROLEC), a qual foi negativa e fraca $(\mathrm{r}-0,204)$ e significativa no nível de 5\% $(0,021)$. Foi negativa porque quanto maior a quantidade de acertos no PROLEC, menor foi a quantidade de espelhamentos observados de números, ou seja, quanto mais os participantes conheciam o sistema de escrita, menos tendência de espelhar os números, embora a correlação tenha sido fraca. A correlação entre as variáveis Escrita Espelhada do Nome e a variável conhecimento linguístico foi negativa e moderada $(\mathrm{r}-0,315)$ e significativa no nível de $1 \%(0,000)$. Foi negativa porque, em geral, só espelharam participantes com pouco conhecimento do sistema de escrita. À medida que aumentava o conhecimento do sistema de escrita, havia, mesmo que apenas moderadamente, a tendência de diminuírem os indícios de espelhamento. Destaca-se que boa parte dos participantes 
não responderam a tarefa de escrita do nome, pois não dispunham do conhecimento linguístico suficiente para a realização da tarefa.

Comparamos, também, indícios de espelhamento dos escolares desta pesquisa com sexo. Conforme a Tabela 6, as médias do total de indícios de produção espelhada e Indício de reconhecimento espelhado são muito semelhantes para os níveis de produção e reconhecimento. O sexo feminino no nível da produção apresentou média de 3,69 enquanto os participantes do sexo masculino apresentaram 3,47 de média. No nível do reconhecimento, as participantes do sexo feminino apresentaram 7,51, enquanto os do sexo masculino apresentaram média de 7,50 com diferença mínima de um décimo, o que leva ao entendimento que não há diferença estatisticamente significativa quando se avalia a produção e reconhecimento de produção espelhada na comparação entre os sexos feminino e masculino dos participantes envolvidos nesse estudo, embora se observe uma leve diferença matemática.

Tabela 6. Correlações entre total de indícios de produção espelhada e reconhecimento de produção espelhada em comparação por sexo.

\begin{tabular}{cccccc}
\hline & Sexo & N & Média & $\begin{array}{c}\text { Erro } \\
\text { Desvio }\end{array}$ & $\begin{array}{c}\text { Erro padrão da } \\
\text { média }\end{array}$ \\
\hline $\begin{array}{c}\text { Indícios produção } \\
\text { espelhada }\end{array}$ & $\mathrm{F}$ & 67 & 3,69 & 2,566 &, 313 \\
$\begin{array}{c}\text { Indício de } \\
\text { reconhecimento } \\
\text { espelhado }\end{array}$ & $\mathrm{F}$ & 67 & 7,51 & 1,580 &, 193 \\
\hline
\end{tabular}

Fonte: Silva (2020).

A Tabela 7 destaca os resultados dos participantes no teste de lateralidade, elaborado para a finalidade deste estudo. $\mathrm{O}$ objetivo deste teste foi avaliar a noção de lateralidade (esquerda, direita, cima, baixo) e sua possível relação com dados das tarefas de espelhamento. Conforme os dados da referida tabela, os percentuais de acerto mostram que $57 \%$ de acertos para a indicação da esquerda e 62\% para as indicações da direita; $87 \%$ de acertos para indicação cima e 79\% para a indicação frente. Observamos que a noção esquerda e direita é mais suscetível a erro se comparado com a noção cima e baixo. Numa perspectiva diferente, cabe destaque que $43 \%$ ainda apresenta dificuldade em sinalizar à esquerda e $38 \%$ apresenta dificuldades para a indicação à direita.

Tabela 7. Resultado do Teste de Lateralidade.

Número de escolares que acertaram as tarefas de lateralidade

\begin{tabular}{lcccc}
\hline Direção & Direita & Esquerda & Cima & Frente \\
\hline Acertos & 80 & 74 & 113 & 102 \\
Percentual & $62 \%$ & $57 \%$ & $87,5 \%$ & $79 \%$ \\
\hline
\end{tabular}

Fonte: Silva (2020). 
Estes dados corroboram com outros estudos que afirmam que o nosso cérebro não está preparado para a (dis)simetrização e simetrização em especial quando a direções esquerda e direita.

O Gráfico 5 apresenta a classificação dos escolares segundo a dominância manual. Para essa avaliação, utilizou-se instrumento adaptado de Annet (1967, in Briggs; Nebes, 1975), que avalia essa variável e também apresenta um barema ${ }^{4}$ para a classificação ${ }^{5} .71 \%$ da população avaliada foi classificada como destra, $22 \%$ como ambidestra e $7 \%$ como canhotas.

Gráfico 1. Classificação dos participantes quanto à dominância manual.

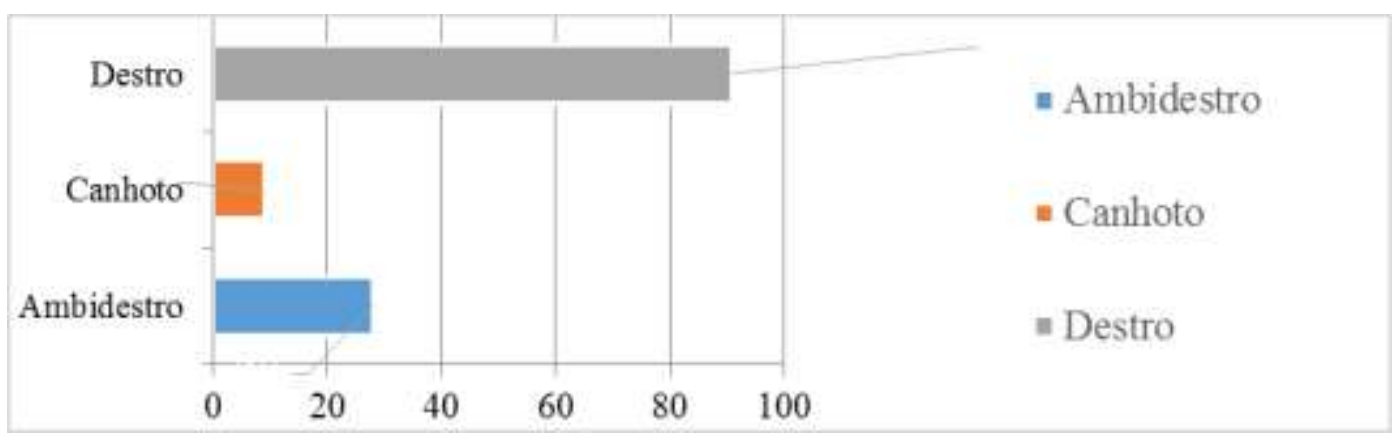

Fonte: Silva (2020).

A Tabela 8 apresenta os resultados dos escolares destros e canhotos, considerando as variáveis dominância manual e indícios de espelhamento. No que diz respeito ao total de indícios de produção espelhada, como é possível ver na tabela 10 , houve pouca diferença entre as médias de canhotos $(3,80)$ e destros $(3,46)$. Quanto avaliada a dominância manual no nível do reconhecimento de produção espelhada, os canhotos apresentam maior média $(8,40)$ e enquanto que os destros $(7,53)$. Submetidos à análise estatística, embora observemos pequenas diferenças matemáticas, as médias não se mostraram diferentes.

Tabela 8. Resultados da avaliação de Dominância Manual.

\begin{tabular}{cccccc}
\hline & Classificação & N & Média & Erro Desvio & $\begin{array}{c}\text { Erro padrão da } \\
\text { média }\end{array}$ \\
\hline Total indícios & Canhoto & 10 & 3,80 & 2,741 &, 867 \\
produção espelhada & Destros & 91 & 3,46 & 2,605 &, 273 \\
Reconhecimento de & Canhotos & 10 & 8,40 &, 843 &, 267 \\
produção espelhada & Destros & 91 & 7,53 & 1,662 &, 174 \\
\hline
\end{tabular}

Fonte: Silva (2020).

Como é possível ver na Tabela 9, há uma fraca correlação entre inteligência e indício de reconhecimento espelhado (0,163, sig 0,065) e entre inteligência e indícios de produção espelhada $(-0,256$, sig 0,003).

\footnotetext{
${ }^{4}$ Adaptado de Annet 1967, in Briggs; Nebes, 1975

${ }^{5}$ Destaca-se que para essa avaliação foram feitas adaptações com a utilização de brinquedos, no caso de crianças menores de 7 anos, com o objetivo de avaliar mais fidedignamente a dominância manual.
} 
Tabela 9. Correlações entre reconhecimento, produção, conhecimento linguístico, eficiência intelectual e lateralidade.

\begin{tabular}{llccccc}
\hline & $\begin{array}{c}\text { Total } \\
\text { Reconhecime } \\
\text { nto }\end{array}$ & $\begin{array}{c}\text { Total tarefas } \\
\text { de produção }\end{array}$ & $\begin{array}{c}\text { PROLE } \\
\text { C - } \\
\text { Total }\end{array}$ & $\begin{array}{c}\text { WASI } \\
- \text { Total }\end{array}$ & $\begin{array}{c}\text { Total } \\
\text { Lateralidad } \\
\text { e }\end{array}$ \\
\hline Total & Correlação de Pearson & 1 &, $182^{*}$ &,- 067 &,- 163 &, $240^{* *}$ \\
Reconheci & Sig. (2 extremidades) & &, 039 &, 451 &, 065 &, 006 \\
mento & N & 129 & 129 & 129 & 129 & 129 \\
Total & Correlação de Pearson &, $182^{*}$ & 1 &,$- 190^{*}$ &,$- 256^{* *}$ &,- 045 \\
tarefas de & Sig. (2 extremidades) &, 039 & &, 031 &, 003 &, 616 \\
produção & N & 129 & 129 & 129 & 129 & 129 \\
PROLEC & Correlação de Pearson &,- 067 &,$- 190^{*}$ & 1 &, $303^{* *}$ &, 012 \\
- Total & Sig. (2 extremidades) &, 451 &, 031 & &, 000 &, 893 \\
& N & 129 & 129 & 129 & 129 & 129 \\
WASI - & Correlação de Pearson &,- 163 &,$- 256^{* *}$ &, $303^{* *}$ & 1 &, 017 \\
Total & Sig. (2 extremidades) &, 065 &, 003 &, 000 & &, 852 \\
& N & 129 & 129 & 129 & 129 & 129 \\
Total & Correlação de Pearson &, $240^{* *}$ &,- 045 &, 012 &, 017 & 1 \\
Lateralida & Sig. (2 extremidades) &, 006 &, 616 &, 893 &, 852 & \\
de & N & 129 & 129 & 129 & 129 & 129 \\
\hline
\end{tabular}

*. A correlação é significativa no nível 0,05 (2 extremidades).

**. A correlação é significativa no nível 0,01 (2 extremidades).

Fonte: Silva (2020).

A natureza complexa das inter-relações entre as variáveis do estudo, tanto de indissociação quanto de interdependência entre simetrização do processamento visual de símbolos gráficos e demais variáveis deste estudo, sugere que a consolidação do conhecimento dos diversos aspectos de sistema alfabético de escrita ocorre, está associada às limitações de nossos determinantes biológicos que, embora plásticos, impõem alguma dificuldade à necessária dissimetrização de nosso aparato neurológico de processamento visual para que seja possível a atribuição do valor sonoro das letras de acordo com as convenções de escrita. Observamos que isso é característica não só das letras, mas de outros estímulos visuais, números, sinais gráficos diversos, sinais de pontuação, etc. Ainda, que o espelhamento ocorre tanto no reconhecimento quanto na produção.

Claro também nos parece que esses resultados podem estar relacionados às experiências prévias do indivíduo com material escrito e, naturalmente, com a direção convencionalizada dos textos, das frases, das palavras e letras. Essas experiências podem ser a visualização de outdoors, folders publicitários, culto na igreja onde há a leitura da bíblia, há mensagens em pôsteres, etc. Veja o leitor que não observamos espelhamento de frases mesmo a leitura convencionalizada sendo da esquerda para a direita. Todavia, é conhecimento tão frágil que na atividade de escrever o nome houve escrita da esquerda para a direita simplesmente pelo fato do pedido de escrever a partir do ponto.

De acordo com os resultados observados, as experiências prévias do escolar com material escrito de acordo com as convenções da Língua Portuguesa podem ter impactado as áreas de processamento visual do cérebro, já que, como também mostram os nossos dados, o aparato cognitivo parece não estar preparado para o processamento distintivo da direção, sugerindo o caminho para o qual o sistema tende a se mover por meio do princípio da auto-organização, robustecendo as condições necessárias para a superação do espelhamento na alfabetização.

Para Larsen-Freeman (1997, p. 145 apud Paiva, 2014a, p. 142-3), a instabilidade do sistema pode ser "formada pelo fato de eles serem sensíveis a feedback" e, acrescentamos, à frequência com que o cérebro processa determinado fenômeno. Tudo leva a crer que, por meio de um processamento de estímulos com reiteração de determinado padrão, o qual ocorre pelo fato de o indivíduo viver num ambiente mais ou menos letrado, acontece a emergência gradual - output - de padrões com direção convencionalizada de elementos de escrita, resultado obviamente da interação dos diversos subsistemas linguísticos e de diversas variáveis do âmbito "bio-cognitivo-sócio-histórico-culturais e políticos" (Paiva, 2014a, p. 144). 
À medida que o ensino formal do sistema de escrita ocorre, em que o indivíduo recebe o feedback acerca do valor sonoro das letras e sua associação com determinada direção, informação essa que pode ser entendida como fator estranho ao sistema, já que assumimos o fato de essa competência não ser natural, mas adquirida, pode ocorrer a instauração da instabilidade do sistema, condição para a atuação do princípio da auto-organização para o desenvolvimento de algum aspecto da leitura e da escrita e, naturalmente, na constituição de um estado final que também é transitório.

\section{Considerações Finais}

Em relação à primeira parte de nossa hipótese de trabalho, como foi possível ver na apresentação e na discussão do objetivo específico 1, não houve diferença estatisticamente significativa entre as médias das 4 séries avaliadas, embora as classes de alfabetização já tivessem escolares com conhecimento alfabético. Avaliando as médias das turmas, não observamos redução na média à medida que aumentava o desempenho em leitura e escrita o que nos leva a concluir que os indícios de simetrização / espelhamento continuam, tanto em tarefas de produção quanto em tarefas de reconhecimento, mesmo após o início do conhecimento alfabético no ciclo de alfabetização. Embora saibamos que a sofisticação do processamento visual está relacionada com o desenvolvimento da leitura e da escrita, a dissimetrização ocorre algum tempo após o conhecimento do nome das letras ou do som das letras. Ou seja, a superação da simetrização, ou melhor, o processo de dissimetrização, ou a atribuição distintiva do valor sonoro de determinada direção das letras, é conquista cognitiva que ocorre em níveis linguísticos mais sofisticados de apropriação da escrita, para além da simples decodificação ou codificação.

Os resultados sugerem que o espelhamento é fenômeno relativamente comum no início do processo de alfabetização e, sabemos, é superado à medida que o indivíduo evolui no conhecimento linguístico. Todavia, no que diz respeito à primeira parte de nossa hipótese, não foi possível nem confirmar a hipótese e nem refutar a hipótese, já que ela continua uma hipótese possível. Para avaliar apropriadamente essa hipótese, são necessários estudos com outras populações para responder a essas questões de pesquisa, ou com escolares de séries mais avançadas ou escolares nessas mesmas séries com conhecimentos linguísticos mais robustos. Vale ainda destacar que estudos com adultos a exemplo da Pesquisa de adaptação de Garcia (2008) cujo objetivo foi o de avaliar o processo de simetrização de um silabário em adultos utilizados sinais e símbolos de outro idioma e confirmou a hipótese do espelhamento que ocorre diante do estranho e novo, como acontece com as crianças que estão na fase inicial da alfabetização.

A segunda parte de nossa hipótese foi confirmada, pois não observamos diferença estatística entre indícios de simetrização, tanto em tarefas de reconhecimento quanto de produção, e noções de lateralidade, preferência manual, eficiência intelectual e sexo. Ou seja, embora sejam variáveis que compõem o complexo emaranhado de aspectos que atuam de maneira intercolaborativa e interdependente para a manifestação do fenômeno aqui estudado, e que particularizam o processo de (dis)simetrização de cada indivíduo, ciclo que a Teoria dos Sistemas Adaptativos Complexos chama de variabilidade, as variáveis sexo, preferência manual, noções de lateralidade e eficiência intelectual não são variáveis que, de alguma forma, promovem influência direta no fenômeno, no caso o valor distintivo da direção das letras.

São necessários outros estudos com populações complementares à deste para responder apropriadamente às seguintes questões: há relação entre espelhamento e dificuldade mais acentuada de aprendizado? Há casos em que o recomendado é a busca por ajuda profissional extraclasse? A superação do espelhamento ocorre em que nível de conhecimento linguístico e de maturação biológica? O espelhamento está relacionado ao processamento visual do indivíduo, logo, há diferenças entre reconhecimento e produção espelhada? Ou seja, o que é superado antes, o reconhecimento e depois a produção ou o contrário?

Espera-se que o presente estudo impulsione a realização de estudos futuros no Brasil, tendo em vista sua realidade, aspectos culturais, que investiguem o reconhecimento e a produção de sinais gráficos invertidos e outras direções como os que estão na direção correta com valor sonoro, em especial na aquisição e aprendizado inicial da leitura e da escrita, como 
proposição metodológica importante em especial nos espaços onde é limitado o acesso desses alunos a profissionais que tenham condições de avaliar e reabilitar estas crianças naquilo que limita sua aprendizagem.

Longe de conclusões, essas aproximações finais indicam ainda investigações sobre o espelhamento que explorem tarefas de rotação mental, avaliação e uso da alça visual em escolares e sua percepção do objeto rotacionado bem como a relação entre espelhamento e o uso da alça fonológica como consequência da memória visual especial e também o papel das memórias de trabalho e verbal.

\section{Referências}

Borel-Maisonny, S. (1984). Existe uma patologia da aprendizagem da língua escrita? Resposta de S. Borel Maisonny. In Ajuriaguerra, J. (ed.) - A dislexia em questão: dificuldades e fracassos na aprendizagem da língua escrita. Artes Médicas.

Brasil. (2017) Base Nacional Comum Curricular (BNCC). Educação é a Base. MEC/CONSED/UNDIME.

Briggs G. G., \& Nebes, R. D. (1975). Patterns of hand preference in student population. Cortex; 11: 230-238.

Chakur, C. R. de S. L. (2005). Contribuições da pesquisa psicogenética para a educação escolar. Psic.: Teor. e Pesq., 21(3), 289-296.

Corballis M.C., Hattie J, Fletcher R (2008). Handedness and intellectual achievement: an even-handed look. Neuropsychologia.46(1):374-8.

Coêlho, J. J. A., \& Bergamini, G. B. (2019). Uso da pesquisa quantitativa nas pesquisas em educação: possibilidades e desafios. Revista Saberes da Faculdade São Paulo. 9(1).

Costa, P. D. S. (2018). Metodologias de Pesquisa utilizadas nos Programas de Pós-Graduação em Ciência da Informação do IBICT e UNESP nos anos de 2014 a 2016. Trabalho de Conclusão de Curso de Graduação em Biblioteconomia - Universidade Federal do Pará, Belém.

Cuba dos Santos, C (1975). Dislexia específica de evolução. Editora Sarvier.

Dancey, C. P., \& Reidy, J (2006). Estatística sem matemática para psicologia: usando SPSS para Windows. Artmed.

Dehaene S (2012). Os neurônios da leitura: como a ciência explica a nossa capacidade de ler. Editora Penso.

Garcia, T. M. (2008). Neuroplasticidade: o espelhamento de grafemas na leitura de um silabário. Florianópolis: UFSC, 324 f. Tese (Doutorado em Linguística) - Programa de Pós-Graduação em Linguística, Faculdade de Letras, Universidade Federal de Santa Catarina, Florianópolis.

Gibson, E. J. et al (1963). An analysis of critical features of letters tested by a confusion matrix. In: A Basic Research Program in Reading. Final Report, Cooperative Research Project No. 639, Cornell University and United States Office of Education. ERIC \#: ED002967

Guaresi. R (2016). Neurociência e educação - Entrevista com Felipe Pegado. Revista Virtual Lingu@ Nostr@, 3(1), 155 - 161.

Kohler, C (1984). Disléxicos, disortográficos ou "maus leitores" e "maus escritores"? A resposta de Kohler. In Ajuriaguerra, J. (ed.) - A dislexia em questão: dificuldades e fracassos na aprendizagem da língua escrita. Artes Médicas.

Larsen-Freeman, D (1997). Chaos/complexity science and second language acquisition. Applied Linguistics, 18(2), $141-165$.

Muchielli, R. \& Bourcier, A.L (1979). La dislexia: causas, diagnóstico y reeducacion. Cincel - Kapelusz.

Naschold, A. C., et al (2015). Aprendizado da leitura e da escrita: a ciência em interfaces. EDUFRN, 408 p.

Paiva (2014). Aquisição de segunda língua. São Paulo: Parábola.

Patias, Naiana Dapieve e Hohendorff, Jean Von. (2019). Critérios de qualidade para artigos de pesquisa qualitativa. Psicologia em Estudo, 24 , e43536. https://doi.org/10.4025/psicolestud.v24i0.43536

Rosa Neto, Francisco et al (2013). A lateralidade cruzada e o desempenho da leitura e escrita em escolares. Rev. CEFAC, 15(4), 864-872.

Scliar-Cabral, L (2009). Processamento bottom-up na leitura. Veredas On-line -Psicolinguística - 2/2008, 24-33 - PPG LINGÜÍSTICA/UFJF.

SILVA, L. P. da (2020). O espelhamento no processamento visual de estímulos gráficos e sua possível associação com variáveis linguísticas e cognitivas. Dissertação (mestrado) - Universidade Estadual do Sudoeste da Bahia, Programa de Pós-Graduação em Linguística - PPGLin, Vitória da Conquista, 2020

Smith, F. Compreendendo a leitura: uma análise psicolinguística da leitura e do aprender a ler. Trad. Daise Batista. (4a ed.), Artes Médicas, 423 p., 2003.

Souza, A. C. de; Alexandre, N. M. C., Guirardello, E. de B (2017). Propriedades psicométricas na avaliação de instrumentos: avaliação da confiabilidade e da validade. Epidemiol. Serv. Saúde. 26(3), 649-659. https://doi.org/10.5123/s1679-49742017000300022.

Zorzi, J. L (2003). Aprendizagem e distúrbios da linguagem escrita: questões clínicas e educacionais. Artmed.

Zorzi, J. L (1998). Aprender a escrever - a apropriação do sistema ortográfico. Artes Médicas. 